\title{
Human Epidermal Neural Crest Stem Cells (hEPI-NCSC) - Characterization and Directed Differentiation into Osteocytes and Melanocytes
}

\author{
Oliver Clewes • Alla Narytnyk • Kevin R. Gillinder • \\ Andrew D. Loughney • Alison P. Murdoch • \\ Maya Sieber-Blum
}

Published online: 1 April 2011

(C) The Author(s) 2011. This article is published with open access at Springerlink.com

\begin{abstract}
Here we describe the isolation, characterisation and ex-vivo expansion of human epidermal neural crest stem cells (hEPI-NCSC) and we provide protocols for their directed differentiation into osteocytes and melanocytes. hEPI-NCSC are neural crest-derived multipotent stem cells that persist into adulthood in the bulge of hair follicles. Multipotency and self-renewal were determined by in vitro clonal analyses. hEPI-NCSC generate all major neural crest derivatives, including bone/cartilage cells, neurons, Schwann cells, myofibroblasts and melanocytes. Furthermore, hEPI-NCSC express additional neural crest stem cell markers and global stem cell genes. To variable degrees and
\end{abstract}

Electronic supplementary material The online version of this article (doi:10.1007/s12015-011-9255-5) contains supplementary material, which is available to authorized users.

O. Clewes $\cdot$ A. Narytnyk $\cdot$ K. R. Gillinder $\cdot$ M. Sieber-Blum Institute of Genetic Medicine, and North East England Stem Cell Institute (NESCI), Centre for Life, Newcastle University, Central Parkway,

Newcastle upon Tyne NE1 3BZ, UK

\section{A. D. Loughney}

Maternity Unit, Women's Services, Newcastle upon Tyne

Hospitals NHS Foundation Trust, Royal Victoria Infirmary,

Queen Victoria Road,

Newcastle upon Tyne NE1 4LP, UK

\section{A. P. Murdoch}

Newcastle Fertility Centre at Life, BioScience Centre, International Centre for Life, Times Square,

Newcastle upon Tyne NE1 4EP, UK

M. Sieber-Blum $(\bowtie)$

Institute of Genetic Medicine Centre for Life,

Newcastle University,

Central Parkway,

Newcastle Upon Tyne NE1 3BZ, UK

e-mail: maya.sieber-blum@ncl.ac.uk in a donor-dependent manner, hEPI-NCSC express the six essential pluripotency genes C-MYC, KLF4, SOX2, LIN28, OCT-4/POU5F1 and NANOG. hEPI-NCSC can be expanded ex vivo into millions of stem cells that remain mulitpotent and continue to express stem cell genes. The novelty of hEPI-NCSC lies in the combination of their highly desirable traits. hEPI-NCSC are embryonic remnants in a postnatal location, the bulge of hair follicles. Therefore they are readily accessible in the hairy skin by minimal invasive procedure. hEPI-NCSC are multipotent somatic stem cells that can be isolated reproducibly and with high yield. By taking advantage of their migratory ability, hEPINCSC can be isolated as a highly pure population of stem cells. hEPI-NCSC can undergo robust ex vivo expansion and directed differentiation. As somatic stem cells, hEPINCSC are conducive to autologous transplantation, which avoids graft rejection. Together, these traits make hEPINCSC novel and attractive candidates for future cell-based therapies and regenerative medicine.

Keywords Neural crest · Adult stem cell · Human epidermal neural crest stem cell $\cdot$ EPI-NCSC $\cdot$ hEPI-NCSC . Pluripotency $\cdot$ Bone $\cdot$ Melanocyte

\section{Introduction}

Neural crest-derived multipotent stem cells reside in the periphery during embryogenesis and in the adult organism [1-11]. One such location is the bulge of whisker follicles, as we have shown in the Wnt1-cre::R26R mouse model in which all neural crest cells and dorsal neural tube cells specifically and indelibly express $\beta$-galactosidase [12-14]. According to their location in the bulge by the epidermal 
outer root sheath, the stem cells were thus termed epidermal neural crest stem cells (EPI-NCSC). A neural crest stem cell molecular signature comprising 19 genes that are abundantly and uniquely expressed in mouse embryonic neural crest stem cells and EPI-NCSC, but not in epidermal stem cells or other skin-resident stem cells/progenitors was subsequently defined [15]. The potential of EPI-NCSC has begun to be realized in mouse models of spinal cord injury, where mouse EPI-NCSC grafts led to an improvement in sensory connectivity and touch perception [16-18]. Others have also reported hair follicle derived progenitor cells, both from within [19] and outside [20,21] the bulge region, the latter having shown promise in a model of sciatic nerve injury. Furthermore, multipotent progenitor cells of various ontological origin within skin and hair follicles have been identified and have been termed skin derived precursors (SKPs) [22-27]. Similarly, other human hair folliclederived neural crest-like cells formed spheres in culture following enzymatic digestion of intact hair follicles, and they expressed neuronal markers when injected into the mouse brain $[28,29]$. It remains to be determined whether these cells are identical to hEPI-NCSC, as they are isolated from entire hair follicles and do not show any migratory behaviour. hEPI-NCSC have the distinct advantage that due to their migratory ability they can be isolated with ease as a highly pure population of multipotent stem cells.

The neural crest is a transient embryonic structure that arises during neurulation at the boundary of the neural plate and the somatic ectoderm. Neural crest cells subsequently delaminate from the forming neural tube and migrate to various locations in the embryo to generate a wide array of progeny. Neural crest derivatives include craniofacial bone/ cartilage, meninges, tooth papillae, the autonomic and enteric nervous systems, most primary sensory ganglia, endocrine cells such as the adrenal medulla, smooth musculature of the cardiac outflow tract and great vessels and pigment cells (melanoyctes) of the skin and internal organs [30, 31].

Skeletal abnormalities, bone trauma, osteoarthritis and deteriorating joints are examples of conditions, which severely compromise an individual's quality of life and ability to perform daily tasks of living. Derivation of replacement bone and cartilage is thus of particular interest. Osteogenic differentiation by various methods has been reported for mesenchymal stem cells, adipose cells and bone marrow stem cells [32-34] with others also reporting osteogenic differentiation of neural crest stem cells derived from human embryonic stem cells (hESC) [35], SKPs [36, 37], mouse ESC [38] and cord blood [39]. The advantage of hEPI-NCSC is that the neural crest has the physiological ability to generate bone, as a subset of cranial bones are of neural crest origin [31, 40, 41]. Likewise, melanoyctes are established neural crest derivatives. In hairy skin, they give hair its colour by injecting melanin granules into keratinocytes that form new hair.

In the current study, we present an in-depth characterization of human equivalents of mouse EPI-NCSC. By comparison analyses, we show their neural crest origin. By taking advantage of the migratory ability of neural crest cells, we have developed a culture method that yields a highly pure population of stem cells. Further studies showed that hEPINCSC express all six established pluripotency markers, which may make hEPI-NCSC a convenient source for reprogramming into iPS cells requiring minimal manipulation. Furthermore, proof-of-principle studies show that hEPINCSC can undergo efficient directed differentiation into osteocytes and melanocytes. The former are implicated in regenerative medicine in orthopaedics, whereas the latter could prove useful components of bioengineered skin.

\section{Materials and Methods}

\section{Bulge Explants and Isolation of hEPI-NCSC}

The bulge of adult human hair follicles [42, 43] were micro-dissected as we have described previously [13-15] from pubic hairy skin. De-identified biopsies were obtained with ethical approval (REC REF: 08/H0907/1) from consenting individuals undergoing repeat elective Caesarean sections. The Donor age bracket was 28-41 years. Briefly, hair follicles were dissected and mechanically cleaned of dermal and adipose tissues. The dermal papilla and matrix were removed and discarded, the bulge region excised, cut into 2-3 pieces and placed onto CellStart (Invitrogen, Paisley, UK Cat\# A10142-01) coated 24-well or $35 \mathrm{~mm}$ plates where they adhered to the substratum within $1 \mathrm{~h}$. The explants were incubated in a humidified atmosphere at $37^{\circ} \mathrm{C}$, $5 \% \mathrm{CO}_{2}$ and $5 \% \mathrm{O}_{2}$. To protect cells against oxidative stress, we routinely culture neural crest stem cells at low oxygen tension (see e.g., ref 44 ). It needs to be noted that $5 \%$ oxygen does not constitute hypoxia for hEPI-NCSC, as hypoxia is defined as $\mathrm{O}_{2}$ tension below the normoxic value in a given tissue [45] and oxygen tension in hair follicles ranges between $2.5 \%$ and $0.1 \% \mathrm{O}_{2}$. [46]. Culture medium was NeuroCult XF (Stem Cell Technologies, Grenoble, France Cat\# 05761) supplemented with $10 \mathrm{ng} / \mathrm{ml}$ rhFGF2 (R\&D Systems, Abingdon, UK Cat\# 233-FB), $20 \mathrm{ng} / \mathrm{ml} \mathrm{rhEGF}$ (R\&D Systems Cat\# 236-EG), 1X ITS+3 (Sigma, Poole, UK Cat\# I-2771), 1\% (v/v) FBS (HyClone, Thermo Fisher, Cramlington, UK Cat\# SH30070.02), 1X GlutaMAX (Invitrogen, Cat\# 35050-038), 1X Penicillin/Streptomycin (Sigma Cat\# P0781) and $2.5 \mu \mathrm{g} / \mathrm{ml}$ Amphotericin B (Sigma Cat\# A2942). Four days post onset of emigration of hEPINCSC, bulges were removed with a bent tungsten needle and cells either fixed with $4 \%$ paraformaldehyde (PFA) for 
indirect immunocytochemistry as described below, or dissolved in TRIzol ${ }^{\circledR}$ (Invitrogen, Cat\# 15596-018) for RNA isolation, or isolated by trypsinisation for subculturing. Briefly, for trypsinisation, cultures were rinsed with PBS-EDTA before addition of trypsin (Worthington Biochemical Corporation, Lakewood, NJ, USA. Cat\# LS003703) at $500 \mu \mathrm{g} / \mathrm{ml}$ in PBS-EDTA. Trypsin treatment was stopped with trypsin inhibitor (Sigma Cat\# T6522; $1 \mathrm{mg} / \mathrm{ml}$ ) that was dissolved in culture medium and the cell suspension collected. The same culture medium was used for ex vivo expansion of hEPI-NCSC.

To promote differentiation of bone/cartilage cells in clonal culture, the culture medium was supplemented with BMP2 $(10 \mathrm{ng} / \mathrm{ml})$. For differentiation into neuronal cells, NGF $(20 \mathrm{ng} / \mathrm{ml})$, TGF- $\beta 2(1 \mathrm{ng} / \mathrm{ml})$ and forskolin $(10 \mu \mathrm{M})$ were added. Neuregulin-1 $(10 \mathrm{nM})$ and CNTF $(10 \mathrm{ng} / \mathrm{ml})$ were added to promote differentiation into Schwann cells.

\section{Real Time Quantitative RT-PCR (qPCR)}

For reverse transcription, total RNA was extracted with TRIzol ${ }^{\circledR}$ reagent and treated with DNaseI (Invitrogen Cat\# 18068). cDNA was synthesised using the SuperScript III First Strand synthesis kit (Invitrogen Cat\# 18080-051), with Oligo (dT) priming according to manufacturer's instructions. For quantitative real time PCR (qPCR), reactions consisted of either $\mathrm{RT}^{2}$ Real-Time SYBR Green/ ROX MasterMix (SABiosciences/Tebu-Bio, Peterborough, UK. Cat\# 103PA-012) or SYBR Green JumpStart qPCR MasterMix (Sigma Cat\# S4438), first Strand cDNA template and appropriate $\mathrm{RT}^{2}$ qPCR Primer Set (SABiosciences/Tebu-Bio). Thermo-cycling conditions were: $95^{\circ}$ C, 10 min followed by 40 cycles of $95^{\circ} \mathrm{C}, 15 \mathrm{~s}, 60^{\circ} \mathrm{C}, 60 \mathrm{~s}$ and $70^{\circ} \mathrm{C}, 30 \mathrm{~s}$, performed on an Applied Biosystems 7900 HT thermocycler. Melting curve analysis showed a single amplification peak for each reaction. Ct values for targets were normalised to the average $\mathrm{Ct}$ values of four housekeeping genes (HKG) Glyceraldehyde 3-phosphate dehydrogenase (GAPDH), Tata box binding protein (TBP), succinate dehydrogenase complex subunit A (SDHA) and Glucose-6-phosphate dehydrogenase (G6PD) and expressed as percentage thereof. Fold changes in expression were calculated using the $\Delta \Delta \mathrm{Ct}$ method. Information on primer pair sequences and source is provided in Supplemental Table 1. RNA from human embryonic stem cells was used from cells of the H9 line, which was maintained exactly as described [47].

Indirect Immunocytochemistry

Cultures were fixed with ice-cold 4\% (w/v) PFA in phosphate buffered saline (PBS, Invitrogen, Cat\# 20012) at room temperature (RT) for $30 \mathrm{~min}$, followed by three 20 min PBS washes, blocked with $2 \%$ (v/v) normal goat serum (Sigma Cat\# G9023) in PBS at RT for $20 \mathrm{~min}$. Primary antibody was added, diluted appropriately in PBS, $0.1 \%(\mathrm{v} / \mathrm{v})$ Triton X-100 and incubated overnight at $4^{\circ} \mathrm{C}$. Cultures were then rinsed four times with PBS for $20 \mathrm{~min}$ each, followed by addition of secondary antibody diluted 1:200 in PBS and incubated in the dark for $2 \mathrm{~h}$ at RT. Secondary antibody was removed and four, 20 min PBS washes performed followed by mounting with Vectashield plus DAPI (Vector Laboratories, Peterborough, UK Cat\# H1500) and cover-slipped.

Primary antibodies used were: rabbit anti-MSX2 (1:200) (CeMines, Evergreen, CO, USA. Cat\# AB/ HD19), rabbit anti-SOX10 (1:100) (CeMines Cat\# AB/ HMG4), mouse anti-NESTIN (1:200) (BD Biosciences, Oxford, UK. Cat\# 61158), goat anti-MYO10 (1:200) (Santa Cruz Biotechnology, Santa Cruz, CA, USA. Cat\# SC-23137), mouse anti-ETS1 (1:200) (Santa Cruz Biotechnology Cat\# SC-56674), rabbit anti-ADAM12 (1:200) (Santa Cruz Biotechnology Cat\# SC-25579), goat antiCRMP1 (1:200) (Santa Cruz Biotechnology Cat\# SC46872), goat anti- $\alpha \beta$-crystallin (CRYAB) (1:200) (Santa Cruz Biotechnology Cat\# SC-22391), goat anti-UFD2/ UBE4B (1:200) (Santa Cruz Biotechnology Cat\# SC30840), goat anti-thimet oligopeptidase (THOP1) (1:200) (Santa Cruz Biotechnology Cat\# SC-30579), rabbit antiNANOG (1:1000) (Abcam, Cambridge, UK. Cat\# ab21624), mouse anti-KLF4 (1:100) (Abcam Cat\# ab75486), rabbit anti-LIN28 (1:1000) (Abcam Cat\# ab46020), mouse anti-SOX2 (1:100) (Abcam Cat\# ab75485), rabbit anti-OCT4 (1:1000) (Abcam Cat\# ab19857), mouse anti-C-MYC (1:200) (Abcam Cat\# ab32), mouse anti- $\beta$ III-tubulin (TUBB3) (1:200) (Millipore, Watford, UK. Cat\# MAB1637), rabbit anti-tyrosine hydroxylase (TH) (1:200) (Santa Cruz Biotechnology Cat\# SC14007), rabbit anti-alpha smooth muscle actin (SMA) (1:200) (Abcam Cat\# ab32575), mouse anti-alpha smooth muscle actin (SMA) (1:200) (Sigma Cat\# A5228), rabbit anti-GFAP (1:1000) (Abcam Cat\# ab7260), mouse anticollagen type II (COL2A1) (1:200) (Santa Cruz Biotechnology Cat\# SC-59958), rabbit anti-RUNX2 (1:100) (Abcam Cat\# ab80238), mouse anti-osteocalcin (BGLAP) (1:200) (Abcam Cat\# 13418), rabbit anti-osteopontin (SPP1) (1:200) (Abcam Cat\# ab8448) and rabbit anti-DCT (1:1,000) (Abcam Cat\#ab74073).

Secondary antibodies used were: DyLight- 488 conjugated goat anti-rabbit IgG (Jackson, Newmarket, UK. Cat\# 111485-144), DyLight-594 conjugated goat anti-mouse IgG (Jackson Cat\# 115-515-146), DyLight-488 conjugated donkey anti-goat IgG (Jackson Cat\# 705-485-147) and DyLight-594 conjugated donkey anti-goat IgG (Jackson Cat\# 705-515-147). 


\section{Clonal Cultures}

Cells from primary explants were detached by trypsin treatment, seeded at clonal density $(60$ cells per $35 \mathrm{~mm}$ plate) onto CellStart treated $35 \mathrm{~mm}$ dishes and allowed to attach overnight. The next morning, single cells were identified and circled using a diamond tipped circle scribe (circle diameter $4 \mathrm{~mm}$ ). Single cells in circles that overlapped with another circle were excluded from analysis. Greater than $90 \%$ were single cells and circles overlapped rarely. Clones were then cultured in NeuroCult NSA (Stem Cell Technologies, Cat\# 05752), 1X ITS +3 , 1\% (v/v) FBS, 1X GlutaMAX, 1X Penicillin/Streptomycin and $2.5 \mu \mathrm{g} / \mathrm{ml}$ Amphotericin B plus addition of specific growth factors for differentiation of multiple cell types for up to 42 days at $37^{\circ} \mathrm{C}, 5 \% \mathrm{CO}_{2}, 5 \% \mathrm{O}_{2}$. Human growth factors were from R\&D Systems; BMP2 (Cat\# 355-BEC-010/CF), NGF (Cat\# 256-GF-100/CF), TGF- $\beta 2$ (Cat\# 302-B2-002/CF), Neuregulin-1 (Cat\# 377-HB-050/CF) and CNTF (Cat\# 257NT-010/CF). Forskolin was from Sigma (Cat\# F6886). Cultures were fixed with 4\% PFA for $30 \mathrm{~min}$ and subsequently processed for indirect immunocytochemistry as described for cell type specific markers. For serial cloning, clones were subcloned as follows. A sterile cloning ring was dipped into sterile vacuum grease and placed on top of the clone. The clone inside the cloning ring was rinsed twice with three drops of PBS each and finally three drops of trypsin were added. The cells were then detached by gentle trituration and re-seeded at clonal density.

\section{Differentiation into Osteocytes}

Cells were isolated by trypsinisation and seeded onto CellStart-treated $35 \mathrm{~mm}$ plates at $2.5 \times 10^{3}$ cells per plate. Cultures were grown in AdvanceSTEM osteogenic differentiation medium (HyClone; Thermo Fisher Cat\# SH30877.KT), 1X GlutaMAX, 1X Penicillin/Streptomycin and $2.5 \mu \mathrm{g} / \mathrm{ml}$ Amphotericin B, with 50/50 medium exchanges on alternate days. Cultures were incubated in a humidified atmosphere at $37^{\circ} \mathrm{C}, 5 \% \mathrm{CO}_{2}$ and either $5 \% \mathrm{O}_{2}$ or ambient air for up to 35 days. Alizarin Red S staining of fixed cultures was performed to detect deposition of calcium. Briefly, cultures were washed twice with PBS at RT, stained for $2 \mathrm{~h}$ at RT with 2\% (w/v) Alizarin Red S, pH 4.2 (Sigma Cat\# A5533), followed by three PBS washes and then visualised with an inverted microscope.

\section{Differentiation into Melanocytes}

For in vitro differentiation of hEPI-NCSC into melanocytes, cells were treated with $100 \mathrm{nM}$ Endothelin-3 (Sigma Cat\# E9137), $20 \mathrm{nM}$ Cholera Toxin (Sigma Cat\# C8052), $16.2 \mathrm{mM}$ 12-O-tetra-decanoylphorbol-13-acetate (TPA)
(Sigma Cat\# 79346), for up to 17 days at $37^{\circ} \mathrm{C}, 5 \%$ $\mathrm{CO}_{2}, 10 \% \mathrm{O}_{2}$. The DOPA reaction was performed to enhance the dark melanin hue. Briefly, cultures were fixed with 4\% PFA for $20 \mathrm{~min}$ at RT, followed by three rinses with PBS and incubated at $37^{\circ} \mathrm{C}$ with $5 \mathrm{mM}$ DOPA (Sigma Cat\# D9628) for $3 \mathrm{~h}$. Cells were post-fixed with $4 \%$ PFA for $20 \mathrm{~min}$ at RT, rinsed with PBS and visualised with bright field light microscopy.

\section{Results}

\section{Bulge Explants}

In order to obtain highly pure populations of hEPI-NCSC we took advantage of their predictable migratory behaviour. Cells with stellate morphology emigrated from bulge explants 6-10 days post explantation (Fig. 1 and Supplemental document S-movie.avi). Bulges from early and late anagen phase provided a high percentage of explants that released emigrating cells (Fig. 1). Interestingly, the presence of the dermal sheath was essential for a high yield of bulge explants with emigrating cells. Bulge explants with dermal sheath resulted in hEPI-NCSC emigration from an average of $45.3 \pm 13.0 \%$ of cultured explants (Fig. 1 A-C, F). In contrast, bulge explants devoid of the sheath yielded significantly fewer emigrating cells, whereas no cells emigrated from dermal sheath explants (Fig. 1). We have therefore developed a reliable and highly reproducible method for the culturing of adherent hEPI-NCSC from dissected adult hair follicle bulge explants. It uses a minimally invasive procedure and represents an abundant source of neural crest-derived stem cells.

\section{Neural Crest Origin}

We have defined a neural crest stem cell signature that is common and specific to mouse embryonic neural crest stem cells and mouse EPI-NCSC [15]. One rationale for defining the molecular signature was to use it for the characterisation of human equivalent cells. The neural crest stem cell signature is expressed in hEPI-NCSC (Fig. 2; Supplemental Table 1). Other NCSC genes tested and detected include SOX10, SNAI2, TWIST1, MS1 (Musashi) and p75NTR, thus corroborating the neural crest origin of hEPI-NCSC. Additional stem cell and the pluripotency genes SOX2, CMYC, KLF4, LIN28, POU5F1/OCT4 and NANOG were expressed as well (Fig. 2; Supplemental Table 1). Equally, the majority of hEPI-NCSC express the molecular signature genes at the protein level as determined by indirect immunocytochemistry (Fig. 3). The neural crest stem cell marker SOX10 [48] and the progenitor cell marker NESTIN were both expressed in all cells. Together, these 

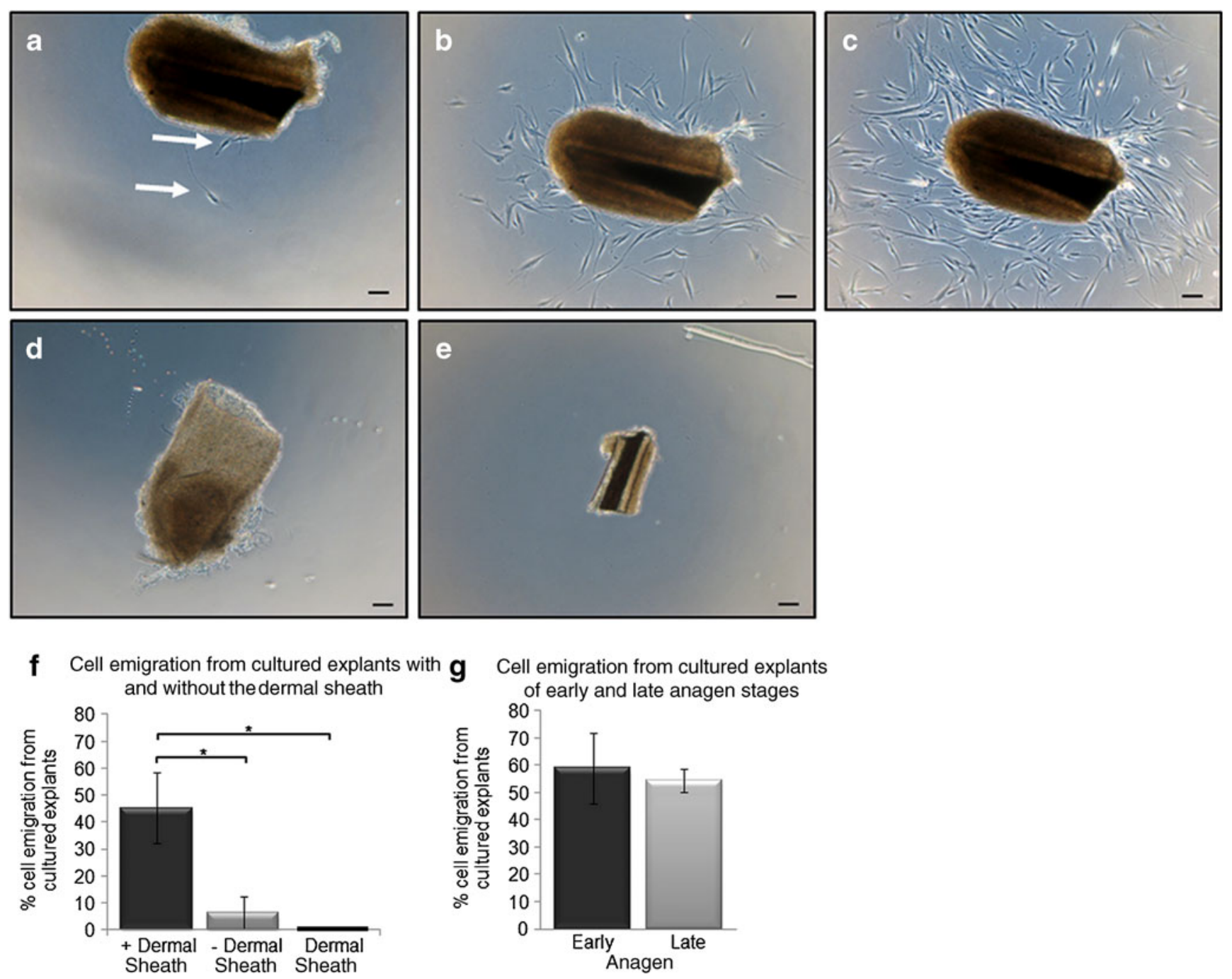

Fig. 1 Primary hEPI-NCSC emigrate from adult hair follicle bulge cultures. (A-C) Bulge explant with cells emigrating onto the CellStart substratum (arrows) at days 6, 8 and 10, respectively. Images are from the same bulge explant. (D) The dermal sheath was removed from the bulge and cultured. (E) Bulge with the dermal sheath removed in culture. No cell emigration or proliferation was seen in $\mathbf{D}$ and $\mathbf{E}$ after 12 days in culture. (F) Percentage cell emigration by day 12 post explanting from bulges cultured with $(45.3 \pm 13.0 \%, n=68)$ and

observations confirm expression of pertinent markers and characterises the bulge-derived cells as neural crest-derived cells.

\section{Multipotency and Self-renewal}

To elicit cell differentiation in clonal cultures, clones were treated with relevant growth factors; BMP2 for bone differentiation, NGF, TGF-b2 and forskolin for neural differentiation, and neuregulin plus CNTF for Schwann cell differentiation. In clonal culture, $67.1 \pm 3.2 \%$ of cloneforming cells generated colonies that consisted of highly proliferative cells (Fig. 4; Supplemental Table 2). The without $(6.3 \pm 6.3 \%, n=46)$ the dermal sheath and the dermal sheath alone $(0 \pm 0 \%, n=29)$. (G) Percentage cell emigration from bulges of early anagen (stage III-IV) follicles $(58.9 \pm 12.8 \%, n=41)$ and late anagen (stages V-VI) follicles $(54.4 \pm 4.3 \%, n=697)$ shows no significant difference in cell emigration from anagen stage hair follicle bulges. Student's $t$-test. Asterisk(s) indicate levels of significant difference as follows: ${ }^{*}, p<0.05$. Scale bars $=100 \mu \mathrm{m}$

remaining cells either died or formed clones consisting of 4-6 non-migratory cells with the flattened morphology of myofibroblasts. Figure 4 shows a primary clone. A single cell is shown that generated four daughter cells within $24 \mathrm{~h}$. By day 7 the clone consisted of hundreds of migratory cells, as seen by the changing shape of the clone. Clones were probed with cell type-specific antibodies in all possible permutations to show that they contained multiple cell types and thus represented multipotent cells (Fig. 5). The cell types were typical neural crest derivatives and included cells with immunoreactivity characteristic of myofibroblasts (smooth muscle actin), bone/cartilage cells (collagen type II; COL2A1), neurons (neuron-specific $\beta$ III- 



Fig. 2 Stem cell gene expression by hEPI-NCSC in primary explant and after ex vivo expansion at the RNA level and time course of expansion. (A) Analysis by qPCR of expression levels of the neural crest stem cell molecular signature, pluripotency genes, other neural crest stem cell genes, general stem cell genes and early lineage genes in primary explants (left; black) and after ex vivo expansion (right, grey). Expression of the neural crest stem cell molecular signature and other neural crest stem cell genes validates the neural crest origin of hEPI-NCSC. The data from primary explants are the average of RNA from three donors, whereas the results from ex vivo expanded cells represent the average of two different donors. Significant differences in expression levels are likely to be due to donor-specific differences. Student's $t$-test. Asterisk(s) indicate levels of significant difference as follows: * $p<0.05, * * *, p<0.001$. (B) Growth curve of hEPI-NCSC proliferation during ex vivo expansion. On average three million cells per bulge were obtained within 28 days. Notably, at 28 days cell growth has not yet levelled off but is still in the log phase. Further expansion is thus possible. ND, not detected 

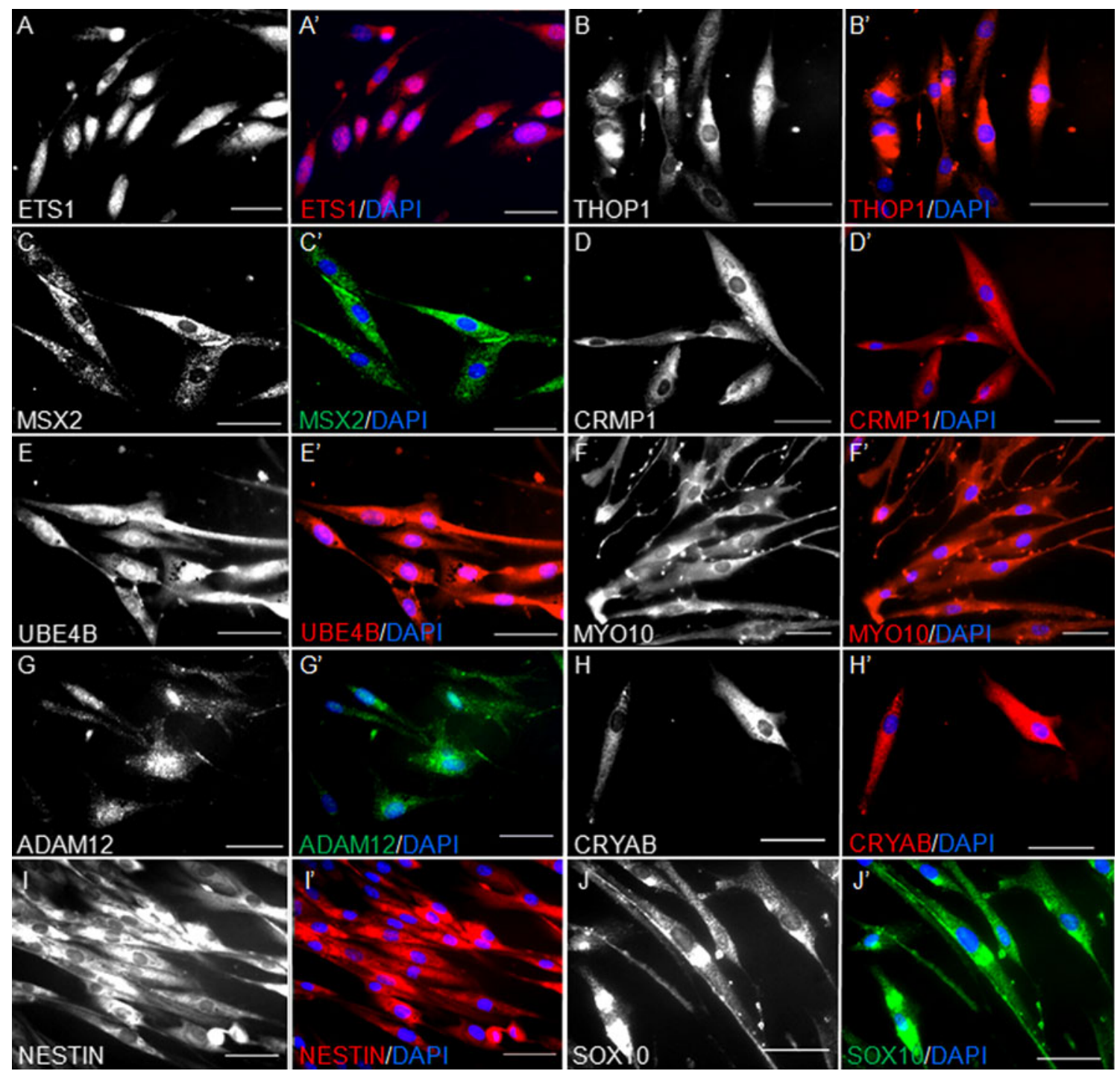

Fig. 3 Indirect immunocytochemistry characterisation of hEPI-NCSC shows expression of NCSC molecular signature and neural crest markers. Staining was performed with available antibodies and dilutions as described on hEPI-NCSC cultures for members of the EPI-NCSC molecular signature and neural crest markers. Images shown for corresponding stains are the antibody specific black and white image plus the colour merged image, with DyLight 488 or DyLight 594 fluorescence and DAPI for the nucleus as appropriate. The transcription factor ETS1 (A and $\mathbf{A}^{\prime}$ ) was expressed in $97.3 \pm 2.7 \%$ cells and had a nuclear localisation. THOP1 (B and B') showed a cytoplasmic location necessary for its roles in protein function and metabolism and was immunoreactive in $100 \%$ of cells. MSX2 $(\mathbf{C}$ and C') is an important transcription factor involved in maintaining the balance between survival and apoptosis in neural crest cells and showed $98.2 \pm 1.8 \%$ expression. CRMP1 (D and $\mathbf{D}^{\prime}$ ) is located in the cytoplasm in $98.3 \pm 1.7 \%$ of cells as it is a cytosolic phosphoprotein

involved with signal transduction pathways. UBE4B ( $\mathbf{E}$ and $\mathbf{E}$ ') is involved in ubiquitination and was seen to have a cytoplasmic localisation in $96.7 \pm 1.6 \%$ of cells. MYO10 (F and $\mathbf{F}^{\prime}$ ) was seen to have a cytoplasmic localisation in $97.6 \pm 2.4 \%$ of cells, consistent with its role in cytoskeletal organisation. ADAM12 (G and $\mathbf{G}^{\prime}$ ) showed a cytoplasmic localisation in $89.0 \pm 6.8 \%$ of cells as it is a membrane anchored protein and has roles in cell-cell and cell-matrix contacts. CRYAB ( $\mathbf{H}$ and $\mathbf{H}^{\prime}$ ) is involved in intracellular structure and subunits act as molecular chaperones and are thus localised to the cytoplasm in $100 \%$ of cells. The intermediate filament protein and stem cell marker NESTIN (I and I') was seen to have a cytoplasmic localisation and expressed in $100 \%$ of cells. The neural crest marker SOX10 (J and $\mathbf{J}$ ') has a role as a nucleo-cytoplasmic shuttle protein and was expressed in $98.6 \pm 1.4 \%$ of cells. DAPI (4', 6-diamidine-2-phenylidole-dihydrochloride) is blue nuclear counter stain. Scale bars $=50 \mu \mathrm{m}$

tubulin [TUBB3], tyrosine hydroxylase [TH]), and Schwann cells (glial fibrillary acidic protein; GFAP). These observations show that multiple cell types can co-exist in the same clone and therefore provide proof that hEPI-NCSC are multipotent. Moreover, these data show that under suitable

culture conditions hEPI-NCSC can generate all major neural crest derivatives.

Self-renewal is an important aspect of stemness. Selfrenewal capability of hEPI-NCSC was determined by serial cloning. Primary clones were detached with trypsin and re- 


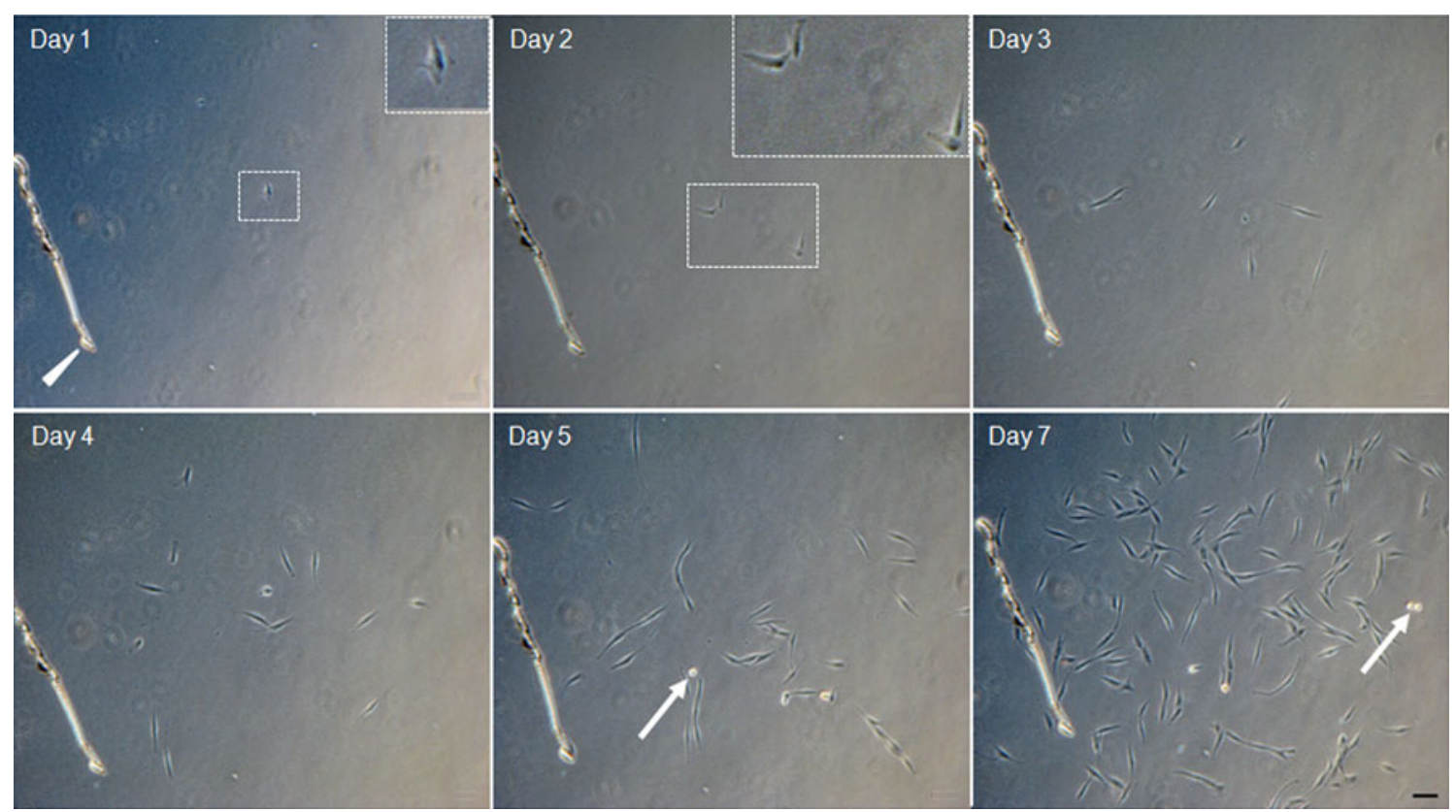

Fig. 4 Single hEPI-NCSC in clonal cultures proliferate and form clones. hEPI-NCSC were isolated by trypsinisation and seeded at clonal density. Single cells were then identified and circled with a diamond tipped circle scribe. (Day 1) Single circled cell (rectangle) and inset, enlarged image of rectangle, (Day 2) four daughter cells (rectangle) and inset, enlarged image of rectangle, following division of the founder cell from Day 1. (Day 3, 4, 5 and 7) shows proliferation of the clone after $3,4,5$ and 7 days respectively such that after 7 days the clone consists of many cells. The dish has been scratched with a tungsten needle (arrow head in Day 1) and orientated so that the field of vision is identical for each image and to show that the clone has derived from a single cell. Arrows in Day 5 and Day 7 show dividing cells. Scale bars $=100 \mu \mathrm{m}$

as expected, expressed at higher levels in hEPI-NCSC than in human embryonic stem cells (Fig. 6).

\section{Ex vivo Expansion}

hEPI-NCSC can be expanded into millions of stem cells without an overall significant loss of stem cell markers (Fig. 2 A, B). Ex vivo expanded cells continued to express the neural crest stem cell molecular signature, pluripotency genes, SOX10, SNAI2, TWIST, MS1 (Musashi), P75NTR, TERT, nestin, and some early lineages genes at the RNA level (Fig. 2A). Expression of the neural crest stem cell molecular signature, SOX10 and nestin, was also tested by immunocytochemistry. All genes were expressed at the protein level (Supplemental Figure 2). Notably, in vitro clonal analysis showed that the majority of in vitro expanded cells remain multipotent and thrive in clonal culture; $53.2 \pm$ $3.6 \%$ of clone-forming expanded cells generated clones that contained multiple cells types; $12.3 \pm 2.6 \%$ died and $34.5 \pm$ $3.0 \%$ stopped dividing (Supplemental Figure 3 ). While early lineage markers were expressed in cells from primary explants and in ex vivo expanded cells, they were not expressed at the protein level (see e.g., dopachrome tautomerase; Supplemental Figure 4). The changes in gene expression levels observed in expansion culture are likely due to donor-specific differences (see also Fig. 6), as due to 

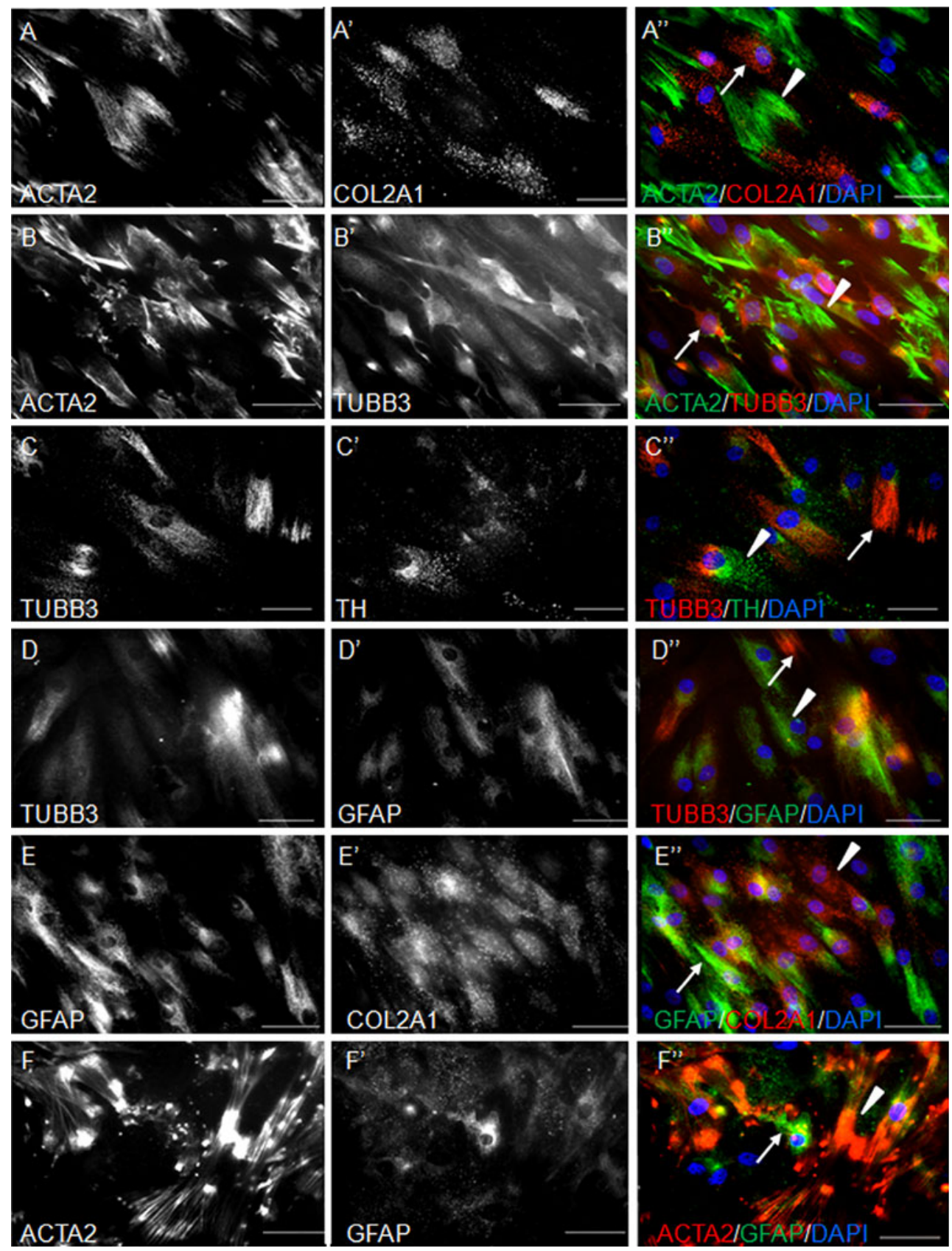

Fig. 5 In vitro clonal analysis shows hEPI-NCSC give rise to multiple cell types. Triple stains combining two cell type specific antibodies (black and white) and coloured merged images using DyLight 488 or DyLight 594 fluorescence and DAPI (blue) nuclear stain. Stains show two cell types are present within clonal cultures. (A, $\mathbf{A}^{\prime}$ and A") Alpha smooth muscle actin (ACTA2) (arrow head), collagen type II (COL2A1) (arrow) and merged images respectively show cells positive for smooth muscle and bone/cartilage markers, with COL2A1 positivity in distinct cells from ACTA2. ACTA2 staining shows a filamentous appearance consistent with its structural role. (B, B' and B') ACTA2 (arrow head), BIII-tubulin (TUBB3) (arrow) and merged images respectively. TUBB3 is a neuronal marker and is positive in subsets of cells in addition to discrete cells being smooth muscle actin positive. Cells positive for TUBB3 also show a neuronal morphology with a cell body and extension of processes (arrow). TUBB3 is seen to be expressed within the cell body and also along the neurites. (C, C' and C") TUBB3 (arrow), tyrosine hydroxylase (TH) (arrow head) and merged images respectively shows protein expression within distinct compartments of cells, as well as indicating that these cells may have a dopaminergic neuron phenotype. (D, D' and D") TUBB3, glial fibrillary acidic protein (GFAP) and merged images show subsets of cells positive for TUBB3 (arrow) or GFAP (arrow head). (E, E' and E") GFAP (arrow), COL2A1 (arrow head) and merged images show cell type specific staining in clonal culture.(F, F' and F") ACTA2, GFAP and merged image shows many cells to be intensely ACTA2 immunoreactive (arrow head), with discrete cells also positive for GFAP (arrow). Scale bars $=50 \mu \mathrm{m}$ 
technical issues the data for primary explants and ex vivo expanded cells were derived from tissue of different donors. On average, three million cells per bulge explant were obtained within 28 days. As illustrated in Fig. 2 B, expansion did not level off at 28 days and therefore, if desirable, could be continued for longer periods of time. Overall, we show that hEPI-NCSC can be expanded ex vivo efficiently and reproducibly and that they retain stemness. An attractive feature of the expansion protocol is its short duration. Changes in the karyotype are thus less of a concern in hEPI-NCSC than in cell lines that are passaged multiple times. The high numbers of stem cells that can be obtained through ex vivo expansion make testing in animal models of human disease and future applications feasible.

\section{Directed Differentiation of hEPI-NCSC into Osteocytes}

Neural crest cells give rise to various craniofacial bones. Developing protocols for the directed differentiation of hEPI-NCSC into osteocytes is thus an obvious first step towards future applications of hEPI-NCSC in cell-based therapies. Here we describe a proof-of-concept protocol for osteogenic differentiation of hEPI-NCSC. Low oxygen tension is the preferred way to expand neural crest stem cells [44] and is currently an accepted culture technique for stem cells. By contrast, in published protocols other types of stem cell are differentiated into osteocytes at ambient oxygen tension. We therefore compared osteogenic differentiation at two different oxygen tensions, $5 \% \mathrm{O}_{2}$ and ambient air. Cultures were analyzed as primary explants and at 7,28 and 35 days of in vitro differentiation. Gene expression at the RNA level was determined by qPCR and at the protein level by indirect immunocytochemistry (Fig. 7). Calcification was shown by histological stain with Alizarin Red S (Fig. 7). Interestingly, transcripts of many osteogenic early lineage markers were already expressed by stem cells in primary explants. These included the essential early lineage genes RUNX2 and CBFB, as well as osteocalcin, osteopontin, collagen type 1 and vitamin D receptor (Fig. 7). Indirect immunocytochemistry showed intense perinuclear RUNX2 immunoreactivity by day 14 (Fig. $7 \mathrm{~A}^{\prime}$ ) in cultures at $5 \% \mathrm{O}_{2}$ and at ambient oxygen tension, respectively (Fig. 7 A"). Similar to the qPCR results, early high RUNX2 immunoreactivity at day 14 was followed by a decrease with progressive cell differentiation. Both qPCR and antibody staining for collagen type II alpha 1 (COL2A1), a marker of bone/cartilage differentiation showed an increase in expression at both $\mathrm{O}_{2}$ conditions over the culture period (Fig. 7 B). Similarly, COL2A1 immunoreactivity was not detected until day 14 with the expected punctuate staining pattern within the cytoplasm (Fig. 7 B'). By day 35, COL2A1 expression levels were similar in both 5\% and ambient air (Fig. 7 B"). Transcripts
Fig. 6 Expression of iPS cell genes in hEPI-NCSC compared to H9 hESC. Expression of pluripotency genes by hEPI-NCSC was compared to $\mathrm{H} 9 \mathrm{hESC}$ by $\mathrm{qPCR}$ and the $\Delta \Delta \mathrm{Ct}$ method used to determine fold differences in expression levels. Three independent donors were assessed (Donor A-C) respectively. SOX10 was used as a marker of neural crest stem cells and in all cases was greater expressed in hEPI-NCSC by approximately 100 fold. C-MYC, KLF4 and surprisingly NANOG were expressed at similar levels in hEPINCSC to hESC. SOX2, LIN28 and POU5F1/OCT4 were however lower. There is also donor variation in expression levels although the trends are similar. hEPI-NCSC from donor three were also analysed for expression of the pluripotency genes at the protein level. Indirect immunocytochemistry was performed with all antibody combinations possible as labelled (A-I"). In all cases, hEPI-NCSC were immunoreactive for the relevant markers. Percentage expression of total cells was determined (J); C-MYC, $100 \pm 0 \%$, KLF4, 56.5 $\pm 6.8 \%$, SOX2, $69 \pm 4.5 \%$, LIN $28,98.8 \pm 0.9 \%$, POU 5 F1/OCT $4,95.7 \pm 1.7 \%$ and NANOG, $92.6 \pm 3.5 \%$. Scale bars $=50 \mu \mathrm{m}$

for osteopontin (SPP1), the main phosphorylated glycoprotein of bone were already present in primary explants and increased with progressing differentiation (Fig. 7 C). At the protein level, osteopontin was significantly higher expressed in cells that were cultured at ambient oxygen compared to cells grown at $5 \%$ oxygen (Fig. 7 C"). Osteocalcin (BGLAP) is a member of the Gla protein family and contributes to the non-collagenous matrix in bone. Like other bonecharacteristic genes, osteocalcin transcripts were detected already in primary explants and expression levels increased with progressing time in differentiation culture (Fig. 7 D). There was no significant difference in the percentage of cells with osteocalcin immunoreactivity between the $5 \%$ oxygen and ambient air culture conditions (Fig. 7 D"). Core-binding factor subunit beta (CBFB) transcripts were already present at high levels in primary explants and remained relatively unchanged throughout the culture period at both oxygen tensions (Fig. 7 E). qPCR for collagen type 1 alpha 1 (COL1A1) (Fig. $7 \mathrm{~F}$ ) showed expression at low levels in primary explants, but increased significantly to high expression levels by day 7 in both oxygen tensions. A significant difference in expression due to oxygen tension was seen at each time point. At the end point, collagen type 1 expression levels were significantly higher in cells that were cultured at $5 \%$ oxygen. Unexpectedly, vitamin D receptor (VDR) transcripts were already present at detectable levels in primary explants (Fig. $7 \mathrm{G}$ ) and remained relatively unchanged throughout the culture period with no significant difference in expression levels at 5\% and ambient oxygen at the end of the culture period. Alizarin Red S staining, which is an indicator of calcium deposits, was intense in cultures at both $\mathrm{O}_{2}$ tensions (Fig. $7 \mathrm{H}^{\prime}$ and $\left.\mathrm{H}^{\prime \prime}\right)$. Overall, we show that hEPI-NCSC can be differentiated efficiently into osteocytes in adherent culture. Whereas individual gene expression levels varied between 5\% and ambient oxygen levels and often differed significantly, the overall trend favours culturing at ambient oxygen tension. 


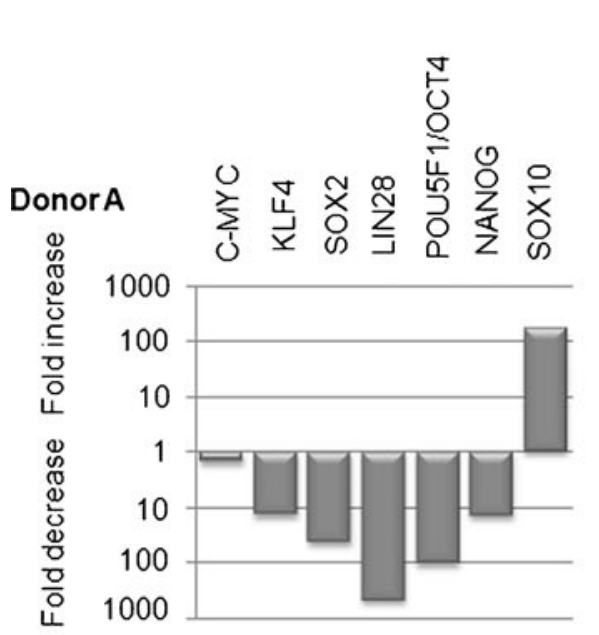

\section{Donor B}


\section{Donor C}
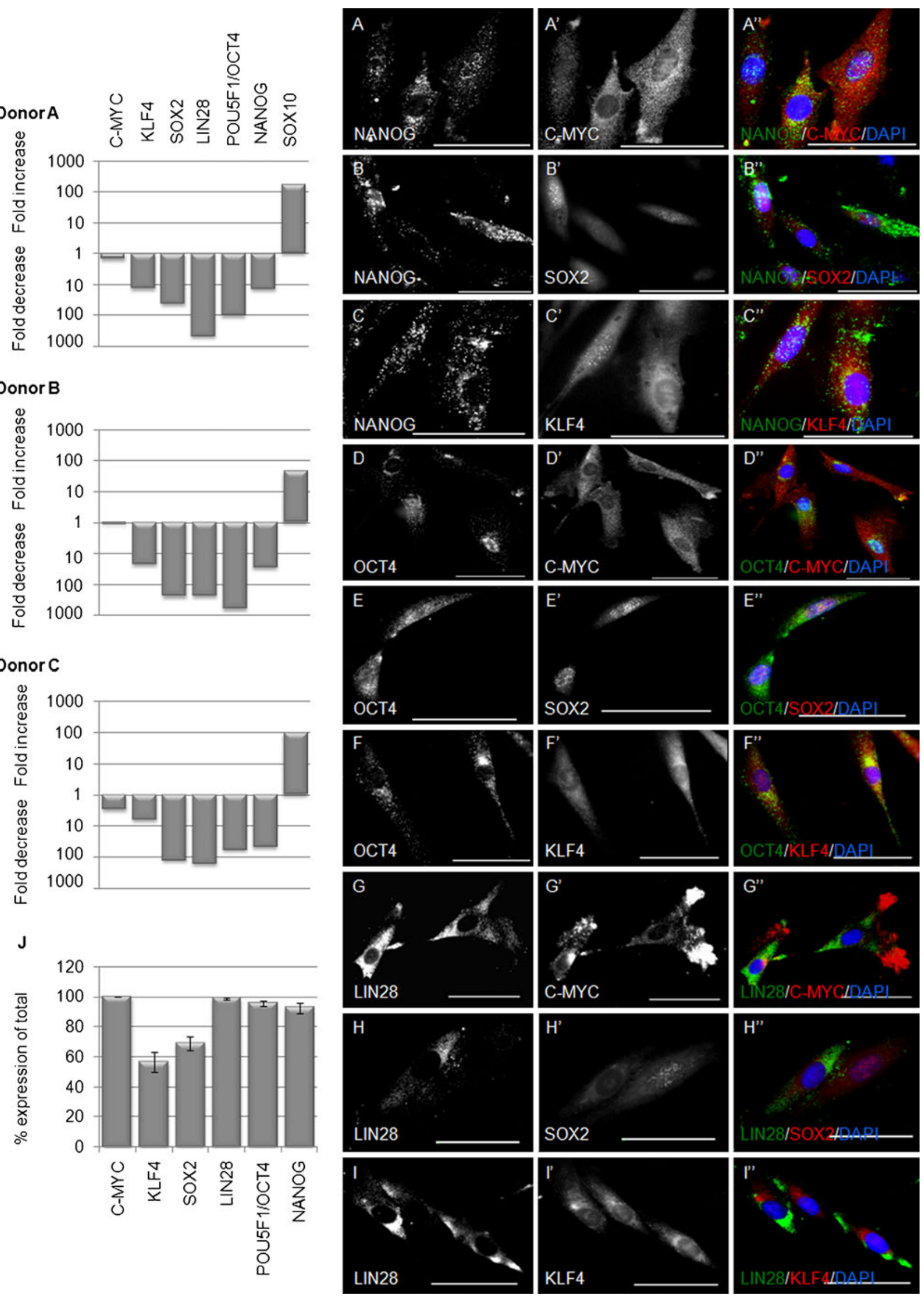



Alizarin Red S

Alizarin RedS

Alizarin RedS

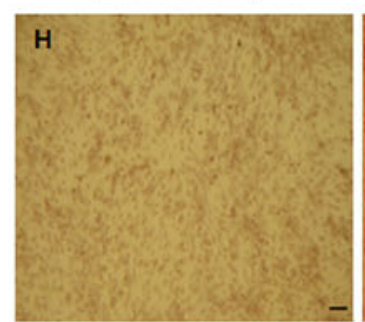

Control d $355 \% \mathrm{O}_{2}$



Experimental d $355 \% \mathrm{O}_{2}$

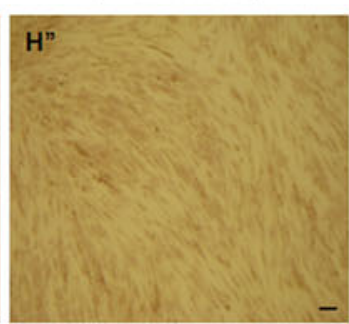

Control d35 ambient $\mathrm{O}_{2}$
Alizarin RedS

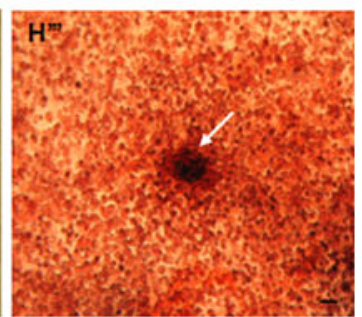

Experimental $\mathrm{d} 35$ ambient $\mathrm{O}_{2}$ 
4 Fig. 7 Osteogenic differentiation of hEPI-NCSC shows expression of key markers. hEPI-NCSC were cultured in AdvanceSTEM Osteogenic differentiation medium at $37^{\circ} \mathrm{C}, 5 \% \mathrm{CO}_{2}$ and either $5 \%$ or ambient $\mathrm{O}_{2}$ for up to 35 days. Cultures were analysed by qPCR or INDIRECT IMMUNOCYTOCHEMISTRY for expression of osteogenic markers. $\mathbf{A}, \mathbf{B}, \mathbf{C}, \mathbf{D}, \mathbf{E}, \mathbf{F}$ and $\mathbf{G}$ show qPCR data for relative expression levels compared to housekeeping genes (HKG) of the appropriate marker as labelled. Primary culture cells $\left(1^{\circ}\right.$ culture) cultured at $5 \% \mathrm{O}_{2}$ as described serve as untreated cells, with experimental cultures treated for up to 35 days. RUNX2 (A) shows an early increase in expression after 7 days in both $\mathrm{O}_{2}$ conditions to $85.5 \pm 0.7 \%$ and $83.4 \pm 1.6 \%$ respectively, which then reduces over the remaining culture period. COL2A1 (B) was seen to increase in expression with time in both $\mathrm{O}_{2}$ concentrations to a comparable final level at day 35 of $59.9 \pm 2.3 \%$ and $61.7 \pm 0.8 \%$ respectively with no expression detected in primary culture cells. Osteopontin (SPP1) (C) was seen to show an initial reduction in expression after 7 days followed by an increase back to a level similar to untreated cells of $76.2 \pm 2.6 \%$ in $5 \% \mathrm{O}_{2}$ cultures at day 35. Culturing at ambient $\mathrm{O}_{2}$ resulted in increasing SPP1 expression over the culture period with $85.9 \pm 2.1 \%$ expression at day 35 . A statistically significant difference was seen in SPP1 expression levels between $\mathrm{O}_{2}$ concentrations at days 7 and 35. Expression of osteocalcin (BGLAP) (D) was shown to increase in both $\mathrm{O}_{2}$ conditions by day 7 to $81.7 \pm 0.6 \%$ and $81.4 \pm 0.3 \%$ respectively and to remain relatively unchanged in both $\mathrm{O}_{2}$ concentrations for the remainder of the culture. Core-binding factor subunit beta $(\mathbf{E})$ was seen to show little change in expression throughout the culture. At day 35 expression levels of 88.8 $\pm 0.64 \%$ and $90.4 \pm 0.2 \%$ were seen for $5 \%$ and ambient oxygen cultures respectively. The oxygen tension affected expression levels significantly at day 7. COL1A1 expression (F) was seen to dramatically increase by day 7 from untreated levels of $104.9 \pm 0.5 \%$ to $125.9 \pm 0.2$ and $122.8 \pm 0.5 \%$ for $5 \%$ and ambient oxygen tensions respectively. Levels then declined and at day 35 were $116.3 \pm 0.8$ and $108.6 \pm 0.4$ respectively. A significant effect of oxygen tension was observed on expression levels at each time point. Expression of VDR (G) was seen to remain virtually unchanged over the 35 day culturing period. Untreated expression levels were $94 \pm 0.6 \%$, with expression level at day 35 being $96.7 \pm 0.4$ and $95.7 \pm 0.9$ respectively. Oxygen tension displayed a significant effect in cultures at days 7 and 28. A' shows RUNX2 immunoreactivity in day 14 cultures at ambient $\mathrm{O}_{2}$. B', C' and D' show COL2A1, SPP1 and BGLAP immunoreactivity respectively, from day 35 cultures at ambient $\mathrm{O}_{2}$. A", B", C" and D" are quantification of respective antibody staining for each marker over the 35 day culture period. Positive expression is expressed as percentage of total cells. RUNX2 expression in both $5 \%$ and ambient $\mathrm{O}_{2}$ cultures was seen to increase by day 14 to $49.0 \pm 2.9 \%$ and $58.4 \pm$ $5.0 \%$ respectively $\left(\mathrm{A}^{\prime}\right)$, followed by a decline and then increase again towards the end of the culture. COL2A1 was not expressed at early time points but increased by day 35 in both $\mathrm{O}_{2}$ conditions with $68.4 \pm$ $4.3 \%$ cells positive from ambient $\mathrm{O}_{2}$ cultures (B"). SPP1 was also seen to increase in expression throughout the culture period with highest expression seen at day 35 in ambient $\mathrm{O}_{2}$ cultures, with $81.1 \pm$ $3.0 \%$ cells positive (C"). A significant difference between $\mathrm{O}_{2}$ concentrations on SPP1 immunoreactivity was seen at days 14 and 35. BGLAP expression was also seen to increase between days 28 and 35 in both oxygen conditions, and was significant at the different oxygen conditions at days 14 and 28 . By day $35,70.7 \pm 7.6 \%$ and 81.1 $\pm 3.1 \%$ cells were immunoreactive from $5 \%$ and ambient $\mathrm{O}_{2}$ cultures respectively (D"). Student's $t$-test. Asterisk(s) indicate levels of significant difference as follows: *, $p<0.05, * * p<0.005, * * * p<$ 0.001. ND $=$ not detected. Scale bars $=20 \mu \mathrm{m} . \mathbf{H}, \mathbf{H}, \mathbf{H}$ " and H" show Alizarin Red S staining of day 35 control and experimental cultures from both $5 \%$ and ambient $\mathrm{O}_{2}$ tensions as labelled. Arrows show regions of positive Alizarin Red S staining in treated cultures, thus indicating calcium deposition, an essential feature of osteogenic differentiation. Scale bars $=100 \mu \mathrm{m}$
Directed Differentiation of hEPI-NCSC into Melanocytes

hEPI-NCSC were differentiated in vitro into melanocytes by adding pertinent growth factors and reagents as described in Materials and Methods. Before and after DOPA reaction, pigmented cells were clearly visible (Fig. 8, arrows), with $65.7 \pm 6 \%$ of cells positive for melanin. Real time PCR data (Fig. 2) shows hEPI-NCSC to express already early lineage markers for melanocytes, including microphthalmia-associated transcription factor (MITF) and dopachrome tautomerase (DCT), which are important for development and function of melanocytes. In stem cells, they were not expressed at the protein level, whereas they were detectable in differentiated melanocytes (Supplemetal Figure 5).

\section{Cryopreservation}

For future applications, it needs to be shown that ex vivo expanded hEPI-NCSC can be frozen, stored frozen, thawed and subsequently grown in culture again. We show here that this is indeed the case. Cells were frozen in $90 \% \mathrm{FBS}$, $10 \%$ DMSO in a Nalgene freezing container (Sigma Cat\# $\mathrm{C} 1562$ ) to $-80^{\circ} \mathrm{C}$ overnight and then transferred to liquid Nitrogen. Subsequently, cells were thawed and re-cultured. Trypan blue stain showed $87 \%$ cell viability after thawing and the cells continued to proliferate (Supplemental Figure 5). We thus show that hEPI-NCSC can be frozen by inexpensive means and thawed again with high yield.

\section{Discussion}

In-depth analyses performed in this study showed that the bulge of human hair follicles contains multipotent neural crest-derived stem cells, which can be expanded ex vivo



Fig. 8 Directed differentiation of hEPI-NCSC into melanocytes. hEPI-NCSC were differentiated into pigmented cells in vitro. DOPA reaction analysis of differentiated cells confirmed expression of pigment in $65.7 \pm 6 \%$ of cells as viewed by bright field microscopy (arrows). Scale bar $=100 \mu \mathrm{m}$ 
and differentiated into osteocytes and melanocytes with high efficiency. Analogous to their equivalent counterparts in mice, the stem cells are termed human epidermal neural crest stem cells (hEPI-NCSC).

hEPI-NCSC have many desirable features, the sum of which makes them a highly attractive type of somatic stem cell. As remnants of an embryonic tissue, the neural crest, hEPI-NCSC have the well-recognized physiological ability to generate a wide array of cell types and tissues. This innate high level of multipotency, combined with the expression of pluripotency genes and efficient ex vivo expansion render this stem cell type conducive not only to autologous transplantation but potentially also to efficient reprogramming into iPS cells.

hEPI-NCSC are readily accessible in the hairy skin by minimal invasive procedure. The patient's own hEPI-NCSC could therefore be harvested, expanded ex vivo and then used for autologous transplantation. hEPI-NCSC are particularly relevant for treatment in spinal cord injury, as neural crest stem cells are ontologically closely related to spinal cord stem cells. Our studies in mouse models of spinal cord injury showed that EPI-NCSC grafts caused a significant improvement in sensory connectivity and touch perception, that they can provide neurotrophic support and angiogenic activity, and that they possibly modulate scar formation by synthesis and release of metalloproteases [16, 18]. It is expected that hEPI-NCSC have similar properties.

Bulges can be dissected with ease. Unlike other procedures [21,29], the isolation technique does not require enzymatic digestion, as in the anagen phase the bulge region reaches into the dermis. Therefore one does not have to deal with the rather inaccessible, collagen-rich dermis, as is necessary with isolating stem cells from levels above the bulge or from intact hair follicles. By taking advantage of their migratory ability, hEPI-NCSC can be harvested as a highly pure population of stem cells without an overt need for further purification, as non-stem cells are not proliferative and within a short time are outgrown by the stem cells and left behind upon subculture. Furthermore, optimization of culture conditions provided bulge explants that produce emigrating hEPI-NCSC with high yield. Ease of isolation, high yield, and rapid ex vivo expansion, along with high purity of the cell population are highly desirable features of hEPI-NCSC and important considerations for cost-effective stem cell production.

We show here that hEPI-NCSC express six established pluripotency genes. Notably, the exact expression levels vary in a donor-specific manner. Age is unlikely to account for these differences, as the age bracket of the three donors tested was 3 years only. The expression of all six pluripotency genes, C-MYC, KLF4, SOX2, LIN28, POU5F1/OCT4, NANOG and SOX10 was not expected and seemingly is unprecedented in somatic stem cells.
Comparison experiments indicate, however, that the genes are expressed at substantially lower levels in hEPI-NCSC than in $\mathrm{H} 9$ embryonic stem cells. Moreover, it remains to be determined whether the pluripotency genes are present in their activated state in hEPI-NCSC. Of particular interest is the observation that virtually all cells expressed at least four of the pluripotency genes, C-MYC, LIN28, POU5F1/OCT4 and NANOG. Conversely, the fact that fewer cells expressed KLF4 and SOX2 indicates that there is heterogeneity within the cell population with regard to expression of pluripotency genes at the protein level.

Interestingly, but not surprisingly, hEPI-NCSC already express early lineage markers even though they are multipotent to a high degree. Expression of early lineage markers in stem cells has been described previously [19, 44, 49]. Expression of early lineage genes for multiple cell lineages, that is the neuronal, glial and melanocyte lineages (Fig. 2) may be an indication that the cells are poised to differentiate into either lineage when exposed to appropriate cues. This notion is in line with our previous data in mouse EPI-NCSC, which showed that all cells express both neuron-specific and glia-specific early lineage genes [18].

Neural crest cells are predestined to give rise to bone and melanocytes, as they generate craniofacial bone [40, 41] and pigment cells of the skin and internal organs [31]. We here show that hEPI-NCSC can be differentiated efficiently into both osteocytes and into melanocytes. While other adult stem cells, such as mesenchymal stem cells [32, 34] and adipocyte stem cells $[50,51]$ are conducive to bone differentiation, hEPI-NCSC have the advantage that they can be accessed fast and safely in the hairy skin as a highly pure population of stem cells without the need for enrichment and purification. We conclude from our data that ex vivo expansion is best carried out at $5 \%$ oxygen, whereas according to most markers tested osteogenic differentiation is preferably performed at ambient oxygen tension, as it has been described in the literature [32, 52].

Hair cycles constantly [53]. We have determined that hair in early and late anagen phase yield hEPI-NCSC. Epidermal stem cells are known to migrate towards the matrix [54, 55], where they give rise to new hair. Likewise, we have observed in mouse hair follicles streams of neural crest-derived cells that appear to head from the bulge towards the matrix [13]. hEPI-NCSC are therefore highly likely to migrate within the hair follicle during anagen phase, in particular as neural crest-derived melanocytes differentiate in the matrix of the hair follicle and thus give hair its colour. During anagen phase, hEPI-NCSC may thus be in an activated stage, or they may progress into a transit amplifying-like progenitor cell compartment. The fact that the dermal sheath needs to cover the bulge in order to trigger efficient cell emigration from bulge explants suggests that there are paracrine interactions between the 
bulge and the dermal sheath, an intriguing observation that warrants further investigation. hEPI-NCSC from different locations in the body may differ by various criteria. This is an important notion that needs to be explored in future studies.

In summary, we have established that hEPI-NCSC are derived from the neural crest and that they represent a type of somatic multipotent human stem cell with considerable potential for future applications in cell-based therapies and regenerative medicine. The novelty and advantageous characteristics of hEPI-NCSC include their easy accessibility in the hairy skin, their high level of purity, their high degree of multipotency, rapid ex vivo expansion and efficient directed differentiation into various clinically relevant cell types. This notion is supported by application trend analysis, which shows that somatic stem cells are coming to the forefront with more than 70 human applications in 2009. Moreover, the final priority value is $60 \%$ for adult stem cells versus $27 \%$ and $13 \%$ for embryonic stem cells and iPS cells, respectively, as determined by analytical hierarchy process [56].

\begin{abstract}
Acknowledgements This work was supported by Medical Research Council Grant 22358, UK (MSB); USPHS grant R01 NS038500-04S1 from the National Institute of Neurological Disease and Stroke, NIH, USA (MSB); the North East England Stem Cell Institute, Newcastle University, Newcastle upon Tyne, UK (MSB) and the Plunkett Family Foundation, Milwaukee, Wisconsin, USA (MSB). We thank Majlinda Lako for providing RNA from H9 human ESC and Elena Taki for her assistance with Alizarin Red S staining and immunocytochemistry.
\end{abstract}

Conflict of interest statement The authors declare no conflict of interest.

Open Access This article is distributed under the terms of the Creative Commons Attribution Noncommercial License which permits any noncommercial use, distribution, and reproduction in any medium, provided the original author(s) and source are credited.

\section{References}

1. Duff, R. S., Langtimm, C. J., Richardson, M. K., \& Sieber-Blum, M. (1991). In vitro clonal analysis of progenitor cell patterns in dorsal root and sympathetic ganglia of the quail embryo. Developmental Biology, 147(2), 451-459.

2. Ito, K., \& Sieber-Blum, M. (1991). In vitro clonal analysis of quail cardiac neural crest development. Developmental Biology, 148(1), 95-106.

3. Richardson, M. K., \& Sieber-Blum, M. (1993). Pluripotent neural crest cells in the developing skin of the quail embryo. Developmental Biology, 157(2), 348-358.

4. Bixby, S., Kruger, G. M., Mosher, J. T., Joseph, N. M., \& Morrison, S. J. (2002). Cell-intrinsic differences between stem cells from different regions of the peripheral nervous system regulate the generation of neural diversity. Neuron, 35(4), 643-656.

5. Kruger, G. M., Mosher, J. T., Bixby, S., Joseph, N., Iwashita, T., \& Morrison, S. J. (2002). Neural crest stem cells persist in the adult gut but undergo changes in self-renewal, neuronal subtype potential, and factor responsiveness. Neuron, 35(4), 657-669.

6. Morrison, S. J., White, P. M., Zock, C., \& Anderson, D. J. (1999). Prospective identification, isolation by flow cytometry, and in vivo self-renewal of multipotent mammalian neural crest stem cells. Cell, 96(5), 737-749.

7. Nagoshi, N., Shibata, S., Kubota, Y., Nakamura, M., Nagai, Y., Satoh, E., et al. (2008). Ontogeny and multipotency of neural crest-derived stem cells in mouse bone marrow, dorsal root ganglia, and whisker pad. Cell Stem Cell, 2(4), 392-403.

8. Nagoshi, N., Shibata, S., Nakamura, M., Matsuzaki, Y., Toyama, Y., \& Okano, H. (2009). Neural crest-derived stem cells display a wide variety of characteristics. Journal of Cellular Biochemistry, 107(6), 1046-1052.

9. Yoshida, S., Shimmura, S., Nagoshi, N., Fukuda, K., Matsuzaki, Y., Okano, H., et al. (2006). Isolation of multipotent neural crestderived stem cells from the adult mouse cornea. Stem Cells, 24 (12), 2714-2722.

10. Ito, K., \& Sieber-Blum, M. (1993). Pluripotent and developmentally restricted neural-crest-derived cells in posterior visceral arches. Developmental Biology, 156(1), 191-200.

11. Sieber-Blum, M., Ito, K., Richardson, M. K., Langtimm, C. J., \& Duff, R. S. (1993). Distribution of pluripotent neural crest cells in the embryo and the role of brain-derived neurotrophic factor in the commitment to the primary sensory neuron lineage. Journal of Neurobiology, 24(2), 173-184.

12. Sieber-Blum, M., \& Hu, Y. (2008). Epidermal neural crest stem cells (EPI-NCSC) and pluripotency. Stem Cell Reviews, 4(4), 256260.

13. Sieber-Blum, M., \& Grim, M. (2004). The adult hair follicle: cradle for pluripotent neural crest stem cells. Birth Defects Research. Part C: Embryo Today, 72(2), 162-172.

14. Sieber-Blum, M., Grim, M., Hu, Y. F., \& Szeder, V. (2004). Pluripotent neural crest stem cells in the adult hair follicle. Developmental Dynamics, 231(2), 258-269.

15. Hu, Y. F., Zhang, Z. J., \& Sieber-Blum, M. (2006). An epidermal neural crest stem cell (EPI-NCSC) molecular signature. Stem Cells, 24(12), 2692-2702.

16. Hu, Y. F., Gourab, K., Wells, C., Clewes, O., Schmit, B. D., \& Sieber-Blum, M. (2010). Epidermal neural crest stem cell (EPINCSC)-mediated recovery of sensory function in a mouse model of spinal cord injury. Stem Cell Reviews, 6(2), 186-198.

17. Sieber-Blum, M. (2010). Epidermal neural crest stem cells and their use in mouse models of spinal cord injury. Brain Research Bulletin, 83(5), 189-193.

18. Sieber-Blum, M., Schnell, L., Grim, M., Hu, Y. F., Schneider, R., \& Schwab, M. E. (2006). Characterization of epidermal neural crest stem cell (EPI-NCSC) grafts in the lesioned spinal cord. Molecular and Cellular Neurosciences, 32(1-2), 67-81.

19. Krejci, E., \& Grim, M. (2010). Isolation and characterization of neural crest stem cells from adult human hair follicles. Folia Biologica (Praha), 56(4), 149-157.

20. Amoh, Y., Li, L., Campillo, R., Kawahara, K., Katsuoka, K., Penman, S., et al. (2005). Implanted hair follicle stem cells form Schwann cells that support repair of severed peripheral nerves. Proceedings of the National Academy of Sciences of the United States of America, 102(49), 17734-17738.

21. Amoh, Y., Kanoh, M., Niiyama, S., Hamada, Y., Kawahara, K., Sato, Y., et al. (2009). Human hair follicle pluripotent stem (hfPS) cells promote regeneration of peripheral-nerve injury: an advantageous alternative to ES and iPS cells. Journal of Cellular Biochemistry, 107(5), 1016-1020.

22. Fernandes, K. J., McKenzie, I. A., Mill, P., Smith, K. M., Akhavan, M., Barnabe-Heider, F., et al. (2004). A dermal niche for multipotent adult skin-derived precursor cells. Nature Cell Biology, 6(11), 1082-1093. 
23. Fernandes, K. J., Toma, J. G., \& Miller, F. D. (2008). Multipotent skin-derived precursors: Adult neural crest-related precursors with therapeutic potential. Philosophical Transactions of the Royal Society of London. Series B: Biological Sciences, 363(1489), 185198.

24. Toma, J. G., Akhavan, M., Fernandes, K. J., Barnabe-Heider, F., Sadikot, A., Kaplan, D. R., et al. (2001). Isolation of multipotent adult stem cells from the dermis of mammalian skin. Nature Cell Biology, 3(9), 778-784.

25. Toma, J. G., McKenzie, I. A., Bagli, D., \& Miller, F. D. (2005). Isolation and characterization of multipotent skin-derived precursors from human skin. Stem Cells, 23(6), 727-737.

26. Hunt, D. P., Morris, P. N., Sterling, J., Anderson, J. A., Joannides, A., Jahoda, C., et al. (2008). A highly enriched niche of precursor cells with neuronal and glial potential within the hair follicle dermal papilla of adult skin. Stem Cells, 26(1), 163-172.

27. Jahoda, C. A., \& Reynolds, A. J. (2001). Hair follicle dermal sheath cells: Unsung participants in wound healing. Lancet, 358 (9291), 1445-1448.

28. Yu, H., Fang, D., Kumar, S. M., Li, L., Nguyen, T. K., Acs, G., et al. (2006). Isolation of a novel population of multipotent adult stem cells from human hair follicles. The American Journal of Pathology, 168(6), 1879-1888.

29. Yu, H., Kumar, S. M., Kossenkov, A. V., Showe, L., \& Xu, X. (2010). Stem cells with neural crest characteristics derived from the bulge region of cultured human hair follicles. Journal of Investigative Dermatology, 130(5), 1227-1236.

30. Le Douarin, N. M., \& Dupin, E. (2003). Multipotentiality of the neural crest. Current Opinion in Genetics \& Development, 13(5), $529-536$.

31. Le Douarin, N. M., \& Kalcheim, C. (1999). The neural crest. New York and Cambridge: Cambridge University Press.

32. Agata, H., Watanabe, N., Ishii, Y., Kubo, N., Ohshima, S., Yamazaki, M., et al. (2009). Feasibility and efficacy of bone tissue engineering using human bone marrow stromal cells cultivated in serum-free conditions. Biochemical and Biophysical Research Communications, 382(2), 353-358.

33. Esposito, M. T., Di Noto, R., Mirabelli, P., Gorrese, M., Parisi, S., Montanaro, D., et al. (2009). Culture conditions allow selection of different mesenchymal progenitors from adult mouse bone marrow. Tissue Engineering. Part A, 15(9), 2525-2536.

34. Hu, J., Feng, K., Liu, X., \& Ma, P. X. (2009). Chondrogenic and osteogenic differentiations of human bone marrow-derived mesenchymal stem cells on a nanofibrous scaffold with designed pore network. Biomaterials, 30(28), 5061-5067.

35. Lee, G., Kim, H., Elkabetz, Y., Al Shamy, G., Panagiotakos, G., Barberi, T., et al. (2007). Isolation and directed differentiation of neural crest stem cells derived from human embryonic stem cells. Nature Biotechnology, 25(12), 1468-1475.

36. Lavoie, J. F., Biernaskie, J. A., Chen, Y., Bagli, D., Alman, B., Kaplan, D. R., et al. (2009). Skin-derived precursors differentiate into skeletogenic cell types and contribute to bone repair. Stem Cells and Development, 18(6), 893-906.

37. Jinno, H., Morozova, O., Jones, K. L., Biernaskie, J. A., Paris, M., Hosokawa, R., et al. (2010). Convergent genesis of an adult neural crest-like dermal stem cell from distinct developmental origins. Stem Cells, 28(11), 2027-2040.

38. Kawaguchi, J., Mee, P. J., \& Smith, A. G. (2005). Osteogenic and chondrogenic differentiation of embryonic stem cells in response to specific growth factors. Bone, 36(5), 758-769.
39. Jager, M., Zilkens, C., Bittersohl, B., \& Krauspe, R. (2009). Cord blood-an alternative source for bone regeneration. Stem Cell Reviews, 5(3), 266-277.

40. Chai, Y., Jiang, X., Ito, Y., Bringas, P., Jr., Han, J., Rowitch, D. H., et al. (2000). Fate of the mammalian cranial neural crest during tooth and mandibular morphogenesis. Development, 127(8), 1671-1679.

41. Jiang, X., Iseki, S., Maxson, R. E., Sucov, H. M., \& Morriss-Kay, G. M. (2002). Tissue origins and interactions in the mammalian skull vault. Developmental Biology, 241(1), 106-116.

42. Paus, R., Muller-Rover, S., Van, D. V., Maurer, M., Eichmuller, S., Ling, G., et al. (1999). A comprehensive guide for the recognition and classification of distinct stages of hair follicle morphogenesis. Journal of Investigative Dermatology, 113(4), 523-532.

43. Stenn, K. S., \& Paus, R. (2001). Controls of hair follicle cycling. Physiological Reviews, 81(1), 449-494.

44. Langtimm-Sedlak, C. J., Schroeder, B., Saskowski, J. L., Carnahan, J. F., \& Sieber-Blum, M. (1996). Multiple actions of stem cell factor in neural crest cell differentiation in vitro. Developmental Biology, 174(2), 345-359.

45. Jezek, P., Plecita-Hlavata, L., Smolkova, K., \& Rossignol, R. (2010). Distinctions and similarities of cell bioenergetics and the role of mitochondria in hypoxia, cancer, and embryonic development. The International Journal of Biochemistry \& Cell Biology, 42(5), 604-622.

46. Bedogni, B., \& Powell, M. B. (2009). Hypoxia, melanocytes and melanoma-survival and tumor development in the permissive microenvironment of the skin. Pigment Cell \& Melanoma Research, 22(2), 166-174.

47. Tilgner, K., Atkinson, S. P., Golebiewska, A., Stojkovic, M., Lako, M., \& Armstrong, L. (2008). Isolation of primordial germ cells from differentiating human embryonic stem cells. Stem Cells, 26(12), 3075-3085.

48. Stemple, D. L., \& Anderson, D. J. (1992). Isolation of a stem cell for neurons and glia from the mammalian neural crest. Cell, 71(6), 973-985.

49. Thomas, S., Thomas, M., Wincker, P., Babarit, C., Xu, P., Speer, M. C., et al. (2008). Human neural crest cells display molecular and phenotypic hallmarks of stem cells. Human Molecular Genetics, 17(21), 3411-3425.

50. Bunnell, B. A., Estes, B. T., Guilak, F., \& Gimble, J. M. (2008). Differentiation of adipose stem cells. Methods Molecular Biology, 456, 155-171.

51. Hayashi, O., Katsube, Y., Hirose, M., Ohgushi, H., \& Ito, H. (2008). Comparison of osteogenic ability of rat mesenchymal stem cells from bone marrow, periosteum, and adipose tissue. Calcified Tissue International, 82(3), 238-247.

52. Siddappa, R., Martens, A., Doorn, J., Leusink, A., Olivo, C., Licht, R., et al. (2008). cAMP/PKA pathway activation in human mesenchymal stem cells in vitro results in robust bone formation in vivo. Proceedings of the National Academy of Sciences of the United States of America, 105(20), 7281-7286.

53. Schneider, M. R., Schmidt-Ullrich, R., \& Paus, R. (2009). The hair follicle as a dynamic miniorgan. Current Biology, 19(3), R132-R142.

54. Blanpain, C., \& Fuchs, E. (2006). Epidermal stem cells of the skin. Annual Review of Cell and Developmental Biology, 22, 339-373.

55. Gambardella, L., \& Barrandon, Y. (2003). The multifaceted adult epidermal stem cell. Current Opinion in Cell Biology, 15(6), 771-777.

56. Frost\&Sullivan, 'Advances in Stem Cells (Technical Insights)" 3 Dec, 2009. 